\title{
Editorial
}

\section{Las ciencias sociales en el desarrollo de procesos de innovación tecnológica}

\author{
Juan Diego Betancur Arias
}

Universidad Católica Luis Amigó

Forma de citar este artículo en APA:

Betancur-Arias, J. D. (2022). Las ciencias sociales en el desarrollo de procesos de innovación tecnológica. Revista Colombiana de Ciencias Sociales, 13(1), 13-16. https://doi.org/10.21501/22161201.4227

En la actualidad, las ciencias sociales siguen conservado una mesura para incorporarse de forma creativa a las acciones sostenibles que permiten el desarrollo de actividades de desarrollo técnico, tecnológico e innovador. Esta cuestión ha hecho que el gap entre conocimiento, ciencia social y desarrollo de la innovación no se encuentre lo suficientemente articulado como para brindar cambios dosificados a la economía social, la innovación cultural y el desarrollo tecnológico y sus sistemas conexos.

Esta reserva temeraria en las ciencias sociales ha desacatado las nuevas lógicas que persigue el pensamiento moderno con relación a la innovación, la investigación para la creación artística y cultural, el desarrollo investigativo en sentido estricto y la modificación de prácticas programáticas e inflexibles propias de los procesos de ciencia en este corpus de conocimiento. Según Estévez (2018), los últimos cinco años han estado caracterizados por procesos de adaptabilidad y trasformación en los modos y formas de hacer ciencia social, que vuelcan la mirada hacia la importancia de la innovación como motor interno de la economía, tal como lo pudo concebir desde sus inicios uno de los grandes precursores de las trasformaciones sociales y culturales por medio de los procesos de ciencia, el economista austriaco Schumpeter (1942).

La tecnología se sigue concibiendo como la pieza más exclusiva de los procesos de desarrollo científico, creación artística y cultural e innovaciones. Al tratarse de una figura sumamente potente, en las estructuras científicas surgen imaginarios y perfiles estilísticos que tratan de comprender, explicar y divulgar las construcciones acerca de los axiomas que configuran el concepto estricto de tecnología.

"Doctor en Psicología con Orientación en Neurociencia Cognitiva Aplicada, integrante del grupo de investigación: Neurociencias Básicas y Aplicadas, Línea: Neurociencia Aplicada a las Organizaciones, Facultad de Psicología y Ciencias Sociales, Universidad Católica Luis Amigó, Medellín-Colombia. Contacto: cienciayacademia@amigo.edu.co 
Si bien la tecnología es la que permite la creación de mecanismos y artefactos al servicio de los sistemas productivos, económicos y sociales, es por medio de la investigación + creación $(\mathrm{I}+\mathrm{C})$ que se puede llegar a generar dichos productos tangibles y susceptibles de mercantilización en los escenarios donde se consume la ciencia, la tecnología y la innovación, es decir, en todo lo que realizamos a diario.

Pensar la tecnología como el resultado de procesos abstractos, tangibles e ingenieriles a nivel científico deja ver las nociones estéticas, no de formas, que poseen los investigadores de las ciencias sociales y humanidades para re- pensarse como actores sociales y científicos capaces de producir tecnología social y cultural al servicio de la sociedad. Esta génesis es entendida en los procesos de investigación, que bien saben seguir investigadores consagrados al saber específico, pero que son obsoletos para la respuesta inmediata, fluctuante y dinamizadora que amerita el contexto productivo de la ciencia, y que hoy se extiende por las innombrables fronteras artísticas y culturales.

Los científicos sociales hemos estado prestos al servicio de los contextos donde ya se han conseguido muchos datos cualitativos y cuantitativos y de los cuales también hemos participado, muy apresurados, en la medición e impacto de fenómenos con métodos ensayados y piloteados en laboratorio; sin embargo, es el momento de indagar sobre las condiciones, competencias, habilidades y talentos de los investigadores contemporáneos, quienes seguimos respondiendo al modelo cienciométrico al escudriñar un lugar importante para la innovación social, la creatividad y la conexión entre formas, métodos, vivencias y escenarios productivos al servicio del ser.

Considerando lo anterior, ha hecho falta un cambio de paradigma al interior de los programas de investigación en ciencias sociales donde los propósitos estén volcados a la innovación técnica, tecnológica y social producto de los avances aplicados que logran desarrollarse por medio de los procesos de investigación. No es exclusivo de la investigación en ciencias naturales la realización de procesos a este nivel, también la investigación aplicada y básica en ciencias sociales y humanidades puede y está en la necesidad de posibilitar, con gran fuerza, el desarrollo de productos tecnológicos y de innovación.

Ahora, la aparición del modelo de innovación triple hélice a mediados de la década del 2000 en el sistema de ciencia, tecnología e innovación de Colombia ha venido produciendo fenómenos coyunturales entre los investigadores y los grupos de investigación que afectan la evolución científica de las ciencias sociales, sus modelos paradigmáticos, la racionalidad instrumental y los enfoques metodológicos para la construcción de resultados científicos que se dirijan al establecimiento de productos amarrados a la naturaleza del desarrollo, la creación artística, cultural y la innovación. La necesidad de realizar cambios en los objetos de estudio y acoger nuevos modelos emergentes que retan a la comercialización de los resultados científicos producto de la actividad 
investigativa son algunos de los intríngulis que se vienen presentando entre los centros de investigación y los investigadores, que para el caso particular en Colombia se encuentran, la gran mayoría de ellos, en las universidades.

Flexibilidad, apertura y des-aprendizajes respecto del
concepto de producción científica tradicional en las ciencias
sociales

El posicionamiento de las nuevas epistemologías del sur, las miradas comprensivas y fenomenológicas, la investigación socio-histórica, la hermenéutica cultural, entre otras formas, métodos o modelos para hacer ciencia, ya nos mostraban que era necesario descentralizar el discurso hegemónico del positivismo y el post-positivismo al servicio de las estructuras científicas. Sin bien nuestro interés está centrado en el paradigma explicativo, no dejamos de reconocer que el mismo ha generado grandes sesgos que apuntan a las miradas sociales bifurcadas que se han gestado entre enfoques cualitativos y cuantitativos, al punto de pensarse, divulgarse y comentarse en los escenarios académicos la debilidad metodológica de las investigaciones de corte interpretativo.

No es justo, científicamente hablando, que un paradigma u otro sea el más regente o el que, en su defecto, genere más o menos producción científica; más bien son las nociones que nos aproximen a conceptos de ciencia abierta para todos, sin jerarquías entre los niveles sociales para acceder a los productos científicos, sin exigencias dadas por el capitalismo cognitivo para transformar los escenarios cotidianos en nuevas formas de apreciar lo real, con licencia para sostenerse en el tiempo.

En la actualidad, se transcurre por una producción que re-cree, re-configure, re-genere toda la fría actividad cienciométrica hacia un conglomerado de atributos, actitudes y disposiciones por parte de los centros de pensamiento y los investigadores en torno a la innovación, la creación artística y cultural, la renovación del plus para los proyectos de $\mathrm{I}+\mathrm{C}$ y el anclaje científico a nuevas estructuras sociales y culturales para dirigir soluciones basadas en métodos sistemáticos con validez ecológica.

Está claro que, al menos en nuestro país, la figura del investigador independiente no existe, ni es bien concebida por nosotros los que nos desempeñamos como científicos al servicio de los centros de pensamiento o universidades. Estamos adheridos a los modelos de ciencia pública, política y social, cuyos elementos en cada uno rigen nuestra praxis. Por tanto, toda la producción debe estar alineada con los criterios de ciencia pública, sin embargo, se presentan algunos baches o dificultades que entorpecen el equilibrio en el desarrollo de tipologías de productos avalados por el Ministerio de Ciencia, Tecnología e Innovación en Colombia. De allí que los investigado- 
res adscritos a los grupos de ciencias sociales y humanidades no logren concretar modelos y métodos diversificados que permitan que otros investigadores de las mismas áreas los puedan tomar como referencia para emprender prácticas relacionadas con la innovación y la creación artística y cultural. Aunque existen el Manual de Frascati, los lineamientos del Manual de Oslo, entre otros, todavía sigue existiendo una mayor inclinación por los productos de nuevo conocimiento, pero sin su utilización para otros desarrollos que derivan de esta misma base. Así que, optimizar la producción científica es una cuestión fundamental para descentralizar las prácticas adheridas al modelo tradicional de hacer ciencia.

\section{Conflicto de intereses}

El autor declara la inexistencia de conflicto de interés con institución o asociación comercial de cualquier índole.

\section{Referencias}

Estévez, H. A. B., Cabanzo, F., Delgado, T. C., Salgar, Ó. H., Soto, A. S. N., \& Salamanca, J. (2018). Apuntes sobre el debate académico en Colombia en el proceso de reconocimiento gubernamental de la creación como práctica de generación de nuevo conocimiento, desarrollo tecnológico e innovación. Cuadernos de Música, Artes Visuales y Artes Escénicas, 13(1), 281-294. https://doi.org/10.11144/javeriana.mavae13-1.asda 